\title{
USING THE REFERENCE FRAMEWORK FOR GOOD MEASLES MANAGEMENT IN PRACTICE - A CASE STUDY FROM NORTH RHINE-WESTPHALIA
}

\author{
Matthias Schröter ${ }^{1}$, Peter Schröder-Bäck², Helmut Brand² \\ ${ }^{1}$ Bioscientia MVZ Jena, Institut für Medizinische Diagnostik, Germany \\ ${ }^{2}$ Department of International Health, Maastricht University, The Netherlands
}

\begin{abstract}
SUMMARY
In 2005, WHO Europe reconfirmed the objective of eradicating measles and fixed a strategy plan for the years 2005 up to 2010. While a downward trend of measles infections in Germany between 2001 and 2004 could be observed, as many as 780 cases of measles were reported in 2005 and in 2006 even 2.281 cases. These high figures in 2006 were almost exclusively caused by an outbreak in the German region of North Rhine-Westphalia. This case study describes how a reference framework for good health management of measles prevention was applied for this region. As a result, various recommendations for action could be given, among them the recommendation to implement individual vaccination reminder systems for parents and bonus systems for parents. Based on these results, a comprehensive policy concept has been drawn up and has become the subject of a political agreement process in this region. Thus this case study shows a paradigm how reference frameworks for good health management can be utilised in practice.
\end{abstract}

Key words: measles, health management, Germany, outbreak, policy making, good practice

Address for correspondence: M. Schröter, Bioscientia MVZ Jena, Institut für Medizinische Diagnostik, Orlaweg 2, D-07743 Jena, Germany. E-mail: matthias.schroeter@bioscientia.de

\section{INTRODUCTION}

In 2005, WHO Europe reconfirmed the objective formulated as early as in 1983 of eradicating measles and rubella as well as preventing congenital rubella infection and fixed a strategy plan for the years 2005 up to 2010 (1). Since the start of the programme, the Federal Republic of Germany has declared its willingness to provide an active contribution to achieve this objective. In 2002, the Health Ministers' Conference reaffirmed that all German states would cooperate with all countries of WHO Europe in realizing the long-term objective of eradicating measles altogether (2). Yet, still some efforts have to be taken in Germany to eradicate measles by improving the federal and regional health management.

Recently, the "Reference Framework for the Health Management of Measles" (3) was developed and published in this journal. This reference framework can be used in practice in a twofold way. On the one hand, it is the foundation of a rapid appraisal method of the existing health management in regions comparing their health management with the health management of other regions. On the other hand, it can be used in practice to give policy makers hints in improving their health policies by listing effective and feasible measures for preventing measles.

In the latter sense, the reference framework could lately be used in North Rhine-Westphalia - the region of Germany with the largest population (ca. 18 millions). This case study reports on the situation of a recent measles outbreak in North Rhine-Westphalia and how the reference framework could then be used in practice to advise in the policy making process.

\section{THE SITUATION IN GERMANY AND NORTH RHINE- WESTPHALIA}

Since the year 2001, the number of annually reported cases of measles has shown a clear downward trend. In 2004, only 28 cases were reported in North Rhine-Westphalia. In the whole of Germany no more than 122 cases were observed. However, this trend has been reversed in 2005 and 2006. Nationally, 780 and even 2,281 cases of measles were reported in 2005 and in 2006 respectively (4). In 2005, North Rhine-Westphalia registered 34 cases and in 2006 even 1,726 cases (Fig. 1). These high figures in 2006 were almost exclusively caused by an outbreak in North Rhine-Westphalia (5). A total of 263 cases needed hospital treatment. Forty-one cases of pneumonia, 39 cases of otitis media and 7 cases of meningitis and/or encephalitis were registered. Thus the frequency of encephalitis/meningitis as the most serious complication accounted for 1/247 notified cases. Unfortunately in January 2007, measles claimed the first victim. Due to a congenital immunodeficiency, a two-year-old boy could not be immunised and contracted the disease as early as in March 2006. He developed severe encephalitis in the course of which he finally died. Meanwhile, a second child who also suffered from severe prolonged encephalitis has died.

The outbreak occurred despite continuously increasing immunisation coverage rates in North Rhine-Westphalia over the last years. Based on school entrance surveys it has been observed that both the first dose immunisation rate and foremost the second dose immunisation rate are continuously increasing. The average 


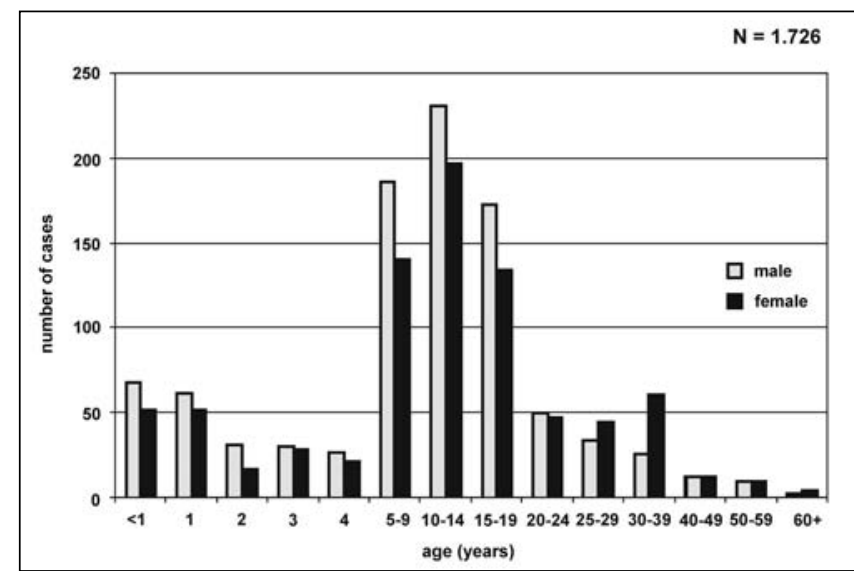

Fig. 1. Number of cases according to age and gender.

first dose immunisation rate has reached the targeted objective of $95 \%$ whereas the rate for the second dose is still clearly below the value of $95 \%$. As expected, the number of measles cases clearly decreased with increasing immunisation rates. It was not before the outbreak in 2006 that this trend was once again reversed. This development gives rise to the assumption that higher immunisation rates in children alone will not be sufficient for reaching the objective of measles eradication in the short run.

\section{THE REFERENCE FRAMEWORK IN PRACTICE}

For this reason, the reference framework (Table 1) developed in the Ben RHM II project was used to determine which further effective and feasible measures could be established (3). This framework is a summary of measures supported by literature and expert opinions and suited for a long-term strategy of measles eradication. These measures are distinguished by different events (first dose immunisation, second dose immunisation and disease). Moreover, different action levels are analysed: The level of the individual, the level of the total population and the level of the overall social system.

An analysis of the situation in North Rhine-Westphalia clearly shows that North Rhine-Westphalia lacks the implementation of many measures (Table 2). Most strikingly, at the population level regarding the first and second dose of immunisation only few measures have been realised, i.e. only three of 13 possible measures all in all. With regard to the different points of time which are being looked at, measures are above all inadequate in the field of first dose immunisation. At the population level, only one of 11, at the level of the individual no more than 6 of 12 and at the level of the social system only 7 of 15 possible measures have presently been implemented in North Rhine-Westphalia. According to this analysis, various recommendations for action can be given, of which four important measures that were identified and recommended for implementation in North Rhine-Westphalia will be described in greater detail below.

\section{Individual Reminder}

During the outbreak, together with the local health authorities and the Robert Koch Institute, the Institute for Public Health,
North Rhine-Westphalia (lögd) carried out a detailed examination at a school where more than 50 cases of measles had erupted. As part of the examination, the parents of those children who had not been immunised against measles were interviewed about possible reasons and causes for not having had their children immunised.

According to this admittedly small-scale survey, an individual reminder would have had a possible benefit in at least $38 \%$ of the cases. If the reminder is combined with information material on the risks of measles disease and the benefit of the immunisation, the benefit to be expected might even be higher. After all, 75\% of the parents who quite consciously refrained from having their children immunised justified their behaviour with the fear of side effects or with the opinion that measles are a harmless disease.

\section{Establishment of Campaigns}

The Standing Immunisation Committee (STIKO) presently recommends a combined measles, mumps and rubella immunisation composed of two doses which should be administered up to the end of a child's 24th month of life. A catch-up campaign which could be aimed at having older children and adolescents without immunisation protection immunised does not exist at the moment. As already reported, the immunisation rate for school beginners has been continuously rising for some years now.

An analysis of the age distribution of the outbreak in North Rhine-Westphalia reveals that the age groups mainly hit by the disease were those between 5 and 20 years. More than $60 \%$ of all cases fell into this age group. This shows that there seem to be considerable gaps in the immunisation coverage rate for this age group. It has therefore to be feared that despite rising immunisation rates in small children the expected decline in the number of diseases will only be very slow if adolescents and young grownups are not included in the immunisation programmes.

\section{Education of Possible Multiplicators}

It is not only the family doctor who has an influence on the immunisation behaviour of parents and children. From what we know, midwives have a very pronounced influence on young parents. But often particularly midwives feel reserved about immunisations, an attitude which could be changed through further training and information campaignes. Teachers and educators also play an important role in the children's health education and often serve as an example. Unfortunately, teachers themselves are often not immunised and are therefore no good example to their pupils. During the above-described measles outbreak, two schools for example were closed for some days because a great number of teachers had not been immunised against measles and because it also could not be clarified whether the teachers had been ill with measles during their childhood.

\section{Bonuses for Parents}

A financial incentive appears suited to motivate many parents who are undecided about immunisation to think about this issue critically and perhaps have their children immunised. Such a bonus system could for example consist of cost reductions for medical examinations when the child enters kindergarten, pro- 
Table 1. Reference framework (slightly simplified from the original)

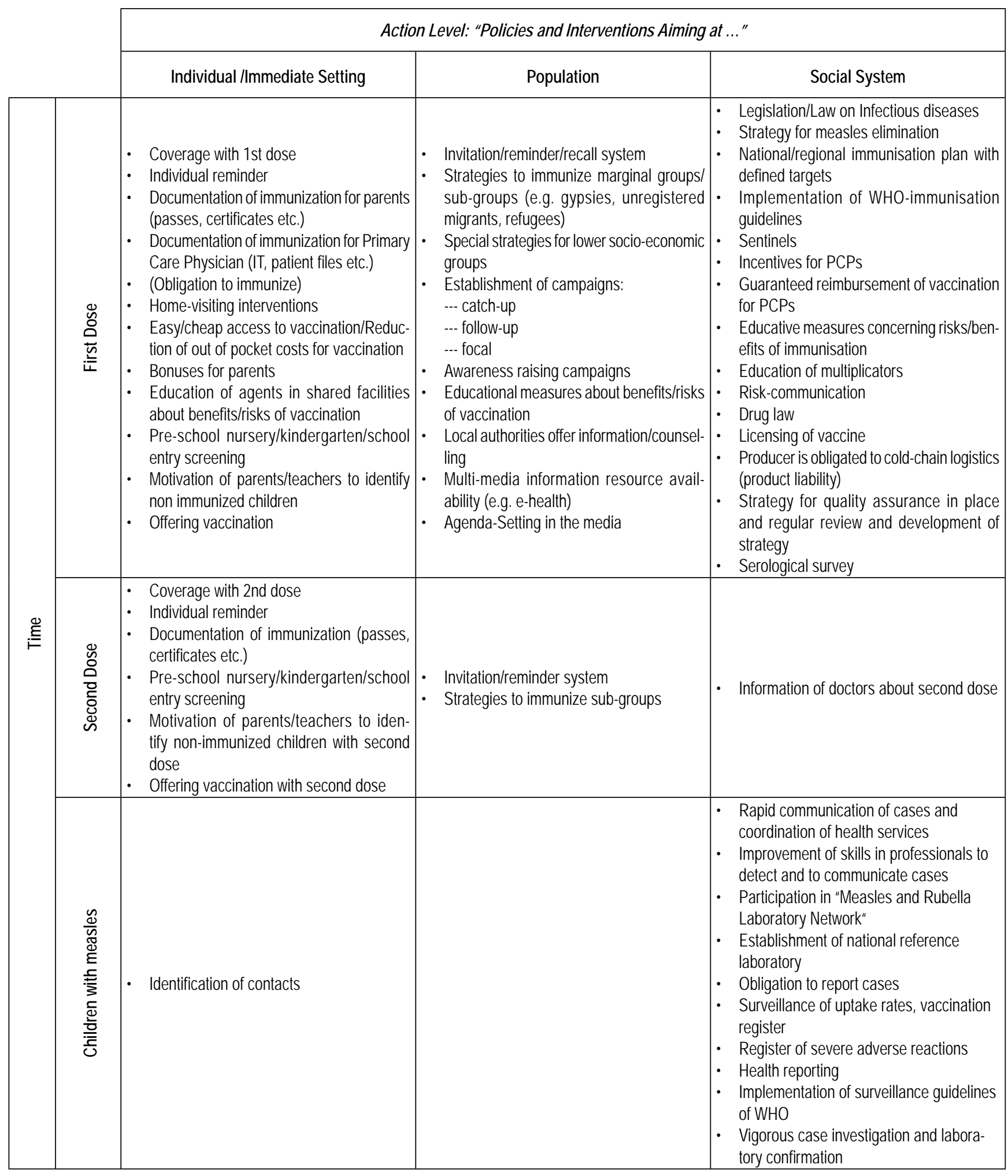

Table 2. Numbers of measures implemented in NRW according to the reference framework

\begin{tabular}{|c|c|c|c|}
\hline & Individual/ Immediate Setting & Population & Social System \\
\hline First dose & $\begin{array}{c}6 / 12 \\
(50 \%)\end{array}$ & $\begin{array}{l}1 / 11 \\
(9 \%)\end{array}$ & $\begin{array}{c}7 / 15 \\
(47 \%)\end{array}$ \\
\hline Second dose & $\begin{array}{c}4 / 6 \\
(67 \%)\end{array}$ & $\begin{array}{c}2 / 2 \\
(100 \%)\end{array}$ & $\begin{array}{c}1 / 1 \\
(100 \%)\end{array}$ \\
\hline Children with measles & $\begin{array}{c}1 / 1 \\
(100 \%)\end{array}$ & & $\begin{array}{c}4 / 10 \\
(40 \%)\end{array}$ \\
\hline
\end{tabular}


vided the child has been immunised. An alternative would be to include parents into the bonus system of their health insurance company if they have their child immunised.

With 1,715 cases last year, North Rhine-Westphalia has seen the biggest measles outbreak since introduction of the Infectious Disease Control Act (IfSG) in 2001. Seven children fell ill with encephalitis or meningitis and two children have died up to now. Against the background of this outbreak, the measures established in North Rhine-Westphalia did not seem to be sufficient in order to reach the objective of WHO Europe and to eradicate measles up to the year 2010. The work carried out under the Ben RHMII project has led to defining important further measures for North RhineWestphalia which could help to still achieve this objective.

\section{CONCLUSIONS}

Based on these results, a comprehensive policy concept has been drawn up and has become the subject of a political agreement process. The Ben RHM II project has thus contributed to the effective improvement of health management within a region.
This can be a paradigm how the reference frameworks can be utilised to improve the public's health in Europe.

\section{REFERENCES}

1. World Health Organization. Eliminating measles and rubella and preventing congenital rubella infection: WHO European Region strategic plan 2005-2010. Copenhagen: WHO Regional Office for Europe; 2005.

2. Conference of State Ministers of Health [homepage on the Internet]. Health in children and adolescents: prevention, early diagnostics and early treatment have to be trengthened. Conclusions of the 75th conference of State Ministers of Health, Düsseldorf 2002 [cited 2009 Mar 15]. Available from: http://www.gmkonline.de/?\&nav=beschluesse_75\&id=75_9.2. (In German.)

3. Brand H, Schröder P, Davies JK, Escamilla I, Hall C, Hickey K, et al. Reference frameworks for the health management of measles, breast cancer and diabetes (type II). Cent Eur J Public Health. 2006 Mar;14(1):3945.

4. Robert Koch-Institut [homepage on the Internet]. SurvStat@RKI [cited 2009 Mar 15]. Available from: http://www3.rki.de/SurvStat/QueryForm. aspx.

5. Schröter M, Wichmann O, Santibanez S, Mankertz A, van Treeck U. Experience with the North-Rhine Westfal meales outbreak in 2006. Westfal Arztebl. 2007;(7):23-5. (In German.)

Received May 25, 2009 Accepted in revised form August 7, 2009 